\title{
Ontological and Aesthetic Qualities of a Singing Sound
}

\section{Qualidades ontológicas e estéticas de um som cantado}

\author{
iD (9) Tatyana Gordeeva1 \\ gordeeva.ksic@rambler.ru \\ (iD) Zagid Azhimov² \\ azhimov.ksic@rambler.ru \\ Kazan State Institute of Culture, Kazan, Rússia \\ iD Raushania Mirnaya ${ }^{3}$ \\ mirnaya.ksic@bk.ru \\ Kazan State Institute of Culture, Kazan, Rússia \\ iD (9) Alfia Voznesenskaya ${ }^{4}$ \\ voznesenskaya.ksic@rambler.ru \\ Kazan State Institute of Culture, Kazan, Rússia
}

Department of Pop and Jazz MusicKazan State Institute of Culture, Kazan, Rússia

\begin{abstract}
Our goal is to reveal the existential qualities of a singing sound associated with a person's spiritual and creative potential. Methods: Unlike any other voice manifestation of a person, a singing sound always represents the ideal area of a person's existence and thus reveals the connection with the individual's mental and creative potential. To reveal these relations, the authors used Heidegger's philosophical aesthetic approach and Sintsov's theory of the 'inexpressible' in art and culture, which examine the ontological foundations of artistic phenomena. Results: the expression of certain continual mental processes that are not directly related to the production and formation of certain meanings should be the initial task of a singing sound. A singing sound can be viewed as a manifestation of artwork (Heidegger) since in its 'material
\end{abstract}

\footnotetext{
1 Candidate of Philosophy, Associate Professor

2 Candidate of Pedagogy, Associate Professor

3 Associate Professor, Department of Pop and Jazz Music, Kazan State Institute of Culture

4 Candidate of Philosophy, Associate Professor
} 
component', it expresses the 'essence' and 'truth' of man as a creator, acts as a source of man's multiple relations with the world ('being-inthe-world'), is characterized as 'composite' due to having an idealisticmaterialistic nature, and contains in itself a reason for self-movement. The source of the entelechy of singing sound is 'inexpressible' and contains all stages of its being ('pre-sounding - sounding - post-sounding'). Conclusions: the revealed qualities of a singing sound, artistry and the connection with the 'inexpressible', allow defining singing sound as an existential phenomenon.

Keywords: being; singing culture; singing sound; artistic creation, 'the inexpressible'.

Resumo. Nosso objetivo é revelar as qualidades existenciais de um som de canto associado ao potencial espiritual e criativo de uma pessoa. Métodos: Ao contrário de qualquer outra manifestação de voz de uma pessoa, um som de canto sempre representa a área ideal da existência de uma pessoa e, portanto, revela a conexão com o potencial mental e criativo do indivíduo. Para revelar essas relações, os autores usaram a abordagem estética filosófica de Heidegger e a teoria do "inexprimível" de Sintsov na arte e na cultura, que examinam os fundamentos ontológicos dos fenômenos artísticos. Resultados: a expressão de certos processos mentais contínuos que não estão diretamente relacionados à produção e formação de certos significados deve ser a tarefa inicial de um som cantado. Um som cantado pode ser visto como uma manifestação de obra de arte (Heidegger), uma vez que em seu "componente material", expressa a "essência" e a "verdade" do homem como criador, atua como uma fonte das múltiplas relações do homem com o mundo ('estar-nomundo'), caracterizado como 'composto' por ter uma natureza idealistamaterialista, e contém em si uma razão de auto movimento. A fonte da enteléquia do som do canto é "inexprimível" e contém todos os estágios de seu ser ("pré-soando - soando - pós-soando"). Conclusões: as qualidades reveladas de um som cantado, a arte e a ligação com o 'inexprimível', permitem definir o som cantado como um fenômeno existencial.

Palavras-chave: ser; cultura do canto; som de canto; criação artística, ‘o inexprimível'. 


\section{Introduction}

A singing sound and singing culture are an important manifestation of the artistic culture of mankind. Numerous trends and branches of singing traditions, as well as vocal schools, which accompanied the cultural development of ethnic groups, evidence that artistic singing is a special phenomenon for human existence.

For example, India's vocal culture has played a primary role in the artistic creativity of the East throughout its history. It gave rise to the unique phenomenon of raga, which represents a special type of Eastern thinking. In the Western tradition, in the XVII-XVIII centuries, bel canto was the apogee of professional singing art in Europe and formed an intellectual singing phenomenon that greatly enhanced the natural potential of the voice.

In the XX century, a landmark phenomenon in Western culture, where the singing trend took a leading position and so far has retained its leadership, became mass music. The beginning of that century saw the emergence of the philosophical interpretation of the crisis phenomena in European culture, reflections on the prevalence of rational principles over the sensual, as well the tendency of apathy and pessimism in society and the search for ways to overcome spiritual stagnation.

This paper considers the singing process as a way intuitively found by modern Western society to help return to its integrity and the reunion of the separated parts of the lost harmony, leading to the understanding of worldview problems. It is a structuring principle in a person's individual and collective existence since it is caused by some reasons that are deeply rooted in the unconscious, as well as in the human intuition and artistic thinking. They easily turn a person's body into a musical instrument, the mastery of which depends on a person's physical-intuitive experience associated with the spiritual potential.

Today, there is no holistic concept of the actual singing sound either in the Western music philosophy or in musicology. There are 
only fragmentary arguments, incomplete definitions and guesses. Meanwhile, it is a fundamental and basic category of singing culture, its 'first brick'. It follows that it is impossible to comprehend the peculiarities of singing culture and to study the patterns of its existence without a deep and systematic understanding of the phenomenon of a singing sound.

The definition of the qualitative characteristics of a singing sound, first of all, its artistic specificity based on immanent sources, its diverse connections with the personality of its creator, as well as with the mental-creative and bodily sources of creation can supplement the knowledge of the origins and the ontological-aesthetic qualities of a singing sound. This contributes to the development of the philosophy of music and the theory of culture and helps to solve the problem of recognizing the actual importance of a singing sound in a person's being and to reveal its role in singing culture.

Thus, the purpose of the article is to determine the existential qualities of a singing sound associated with a person's spiritual and creative potential.

\section{Literature review}

In his work "Voice and Phenomenon", J. Derrida comes to the conclusion that consciousness manifests itself in the voice as being. He defines the voice as a unique phenomenon capable of constituting the ideality of thought and expressing it through a special matter, i.e. a sound that does not have the usual visual form (Cisney, 2014). Nevertheless, there are qualitative differences between speech sounds and a singing sound. One of these differences is the relative independence of musical sounds from the processes of meaning generation, without which speech is deprived of its very foundations.

The work of American singer C. Rogers (1893), "The Philosophy of Singing", is directly addressed to the philosophy of singing. 
She views the essence of opera singing as a harmonious unity of thought, gesture, and voice. The absence of such a unity and the differentiation of a person's three main aspects lead to the problem of disharmonization, which, according to the researcher, is manifested in a loss of expression spontaneity through singing, as well as in the emergence of a barrier between emotion, thought, and corporality. In addition to causing a loss of an individual's ability to sing, the lack of congruence between emotion, thought, and mind is aproblem of disharmony of culture as a whole. The monograph of J. Bicknell (2015) is devoted to the philosophical view of modern singing, which includes the phenomenon of the song genre. N.D. Andguladze's work, "Homo Cantor" (2002), contains generalized data on singing and reflections on the European tradition of opera singing. Citing a number of philosophers' convincing arguments about the interrelation between singing, a singing sound, voice, and a person's being, N.D. Andguladze strives to attract attention to the very ontological status of this phenomenon and to the idea suggesting that the sound of a human voice has a direct impact on the formation of culture. The studies of H.I. Khan (1996) and J. Schaefer (2000) are devoted to the Eastern perception of sound, which is rooted in antiquity and views a singing sound as a reflection of the sound of Universum. Representing the Eastern Sufi philosophy of sound, H.I. Khan believes that sound, vibration is the origin of the entire creation. The philosopher notes that the perception of absolute sound requires full concentration on the process of listening to it (meditation); otherwise, other earthly sounds will muffle it. H.I. Khan views voice as an expression of a person's spirit and as a way of acquiring an interconnection with all its subtle schemes. When analyzing Indian music, J. Shaefer also shows a special attitude to a singing sound. As a performer himself, he notes that the art of instrumental raga can be comprehended only through its vocal origin. Penetrating into a singing sound, Indian researchers demonstrate the profound meaning generated by this phenomenon as a means of communication with Universum. At the same time, it is still unclear whether this is the sole reason for the birth of sound. 
The efforts of foreign musicologists, for example, H.H. Eggebrecht ("Sinn und Gehalt", Wilhelmshaven, 1979), E.M. Hornbostel (Tonart und Ethod", Lpz., 1986) are directed towards studying a musical sound as a center of meaning. E. Kurt's work, "The Fundamentals of Linear Counterpoint", is quite well-known and was translated to Russian and published in Moscow in 1931. E. Kurt views sound as a complex phenomenon originated in the depths of human psyche.

In the modern world, it is hard to imagine the feeling of sound corporality that accompanied the man of Antiquity. In this respect, it is necessary to note the research of Professor E.D. Reznikoff (University of Paris, Department of Philosophy) with his decipherment of neumatic church records of early Christianity and his method of 'antique' singing practiced by him for about forty years. The research works of E.D. Reznikoff (2004) lead to conclusions about the relationship between sound and the deep layers of consciousness, as well as the close consonance of the body and voice.

\section{Methods}

The work is based on a systematic approach to the study of the peculiarities of a singing sound, which allows integrating various theoretical methods and ideas, including:

- the philosophical-ontological method of studying a person's spiritual reality, which is based on the fact that the generic concept of being combines the physical and spiritual as two ways of existence (Menchikov, 2013). In this regard, a singing sound, as a dual phenomenon (bodily-mental), is an important object of philosophical reflection;

- A.F. Losev's (2018) phenomenological method of studying musical phenomena, which allows studying them in the context of the deep foundations of being; 
- M. Heidegger's (2013) fundamental ontological-aesthetic concept of creation, which provides an opportunity to view a singing sound as an individual manifestation of a person's artistic and creative activity embodied in an artwork;

- the concept of the rigidly figurative origins of the 'inexpressible' proposed by E.V. Sintsov, which is the immanent source of the selforganization of artistic formation in art and culture. This concept allows developing and deepening the understanding of a singing sound as an artistic phenomenon.

The research process includes the following stages:

- the analysis of the peculiarities of a cultured singing sound, which makes it possible to reveal its versatility, in particular, its bodily-mental nature, the connection between transmitted meanings and the deep layers of the unconscious, the desire for the infinite continuation of sounds, etc.

- the reflection of a singing sound as an artistic phenomenon, which helps identify its basic property of 'restoring the world' of an individual;

- the study of a singing sound in the context of 'the inexpressible' as the source of its artistic expression, which forms the concept of the three-stage existence of this phenomenon.

\section{Results and Discussion}

\section{Differences between Natural and Cultured Voice Sounds}

First of all, it is necessary to identify the differences between the natural and cultured sounding of the human voice. All voice sounds are united by their physical origin - the larynx, a special organ that contains vocal cords. These sounds can be divided into two groups, given the motives of their occurrence. The sounds of the first group are generated by a reflexive or emotional reaction to the events of the external world. This group includes sounds 
involuntarily emitted by the human larynx, for example, moaning, crying, screaming, groaning from fright, etc. These sound reactions help to endure pain, horror, a strong emotional outburst, etc. This kind of sounds should not be fully bracketed out from a singing sound and singing culture as a whole. Their 'emotional and natural disposition' is one of the components of a potential musical sound. L. Wittgenstein believed that in all great art there is a wild beast (Pavlov, 2015). It is this component of a sound that can subsequently be tamed by a human. This statement is confirmed by the following fact: in the nineteenth century, the outstanding Italian tenor Rubini introduced the method of 'sobbing' into the artistic practice, which had a great emotional impact on the audience. In modern pop singing, a lot of techniques are based on screaming, for example, screaming (wheezing), screamo (falsetto screaming), and harsh (screech).

Natural voice sounds of a person are some kind of original sound matter produced by a person. Like an unprocessed piece of marble turns into a marble statue in the hands of a sculptor, a singer has the ability to endow this sound matter with all the features of cultured sounding.

Speech can also be attributed to this group of sounds since its emergence is also explained by a person's natural need to form social groups that help to survive in the natural environment and actively cultivate it. As evidenced, for example, byM.P. Musorgsky's artistic experiments in Russian culture (Lysenko, 2013), such sounds are forerunners of music.

When a 'natural' sound produced by a person turns into a 'cultured' one, does it become a part and object of singing culture?

To answer the above question, the authors refer to Aristotle, who believed that voice is peculiar only to animate beings. Nevertheless, the philosopher makes a distinction between the human voice and sounds made by animals. Aristotle points to the peculiarity of a person's voice, which is produced neither when they are exhaling nor when they are inhaling but when they hold 
their breath and is accompanied by the emergence of some image. His observation marks the moment of holding the breath prior to sound production as a moment of switching consciousness to the process of sound formation, which essentially violates the natural respiration cycle of 'inhalation-exhalation-pause' and turns it into a triad of 'inhalation-pause-exhalation'. The conclusions are related to the relationship between breathing and meaningful sounds, and the perception of singing as a sounded exhalation, exhalation with a certain degree of awareness of this process. These conclusions allow defining 'cultured' voice sound as the product of meaningful articulation associated with an idea (Andguladze, 2002).

Nevertheless, not every meaningful voice sound is a singing sound. Man has produced a huge number of sounds specially imbued with the representations and work of consciousness. For example, speech. A fairly popular opinion suggests that the phenomenon of singing is a kind of combination of sensuality of melody and rationality of speech. N.D. Andguladze (2002) notes that it is fundamentally wrong to subdivide singing into music and text, implying the constituent parts of this art form. According to the researcher, a determining factor of singing is related to lyricism precisely peculiar to a singing sound.

In addition, there is such a qualitative difference between speech sounds and singing sounds as the relative independence of musical sounds from the process of meaning generation, without which speech is deprived of its very foundations. This peculiarity of music was noted by A.F. Losev (2018). He defines 'becoming' as the basic quality of the musical matter, which distinguishes it from all art forms and makes it the basis for the entire artistic creation of man. The philosopher views musical 'becoming' as a unique process whose products are not specific frozen images, sounds or intonations but, on the contrary, a meaning that changes every moment with every image and sound. This level of meaning goes deep into the human consciousness and, from the world's indefinite original semantic unit, generates its first reflections transmitted through sound matter. In a singing sound, this process 
of becoming presupposes the quality of fluency (the sound flows), temporal and spatial extension. It is dominated by the image of the infinite and continuous as the main peculiarity of Universum. K.S. Stanislavski (2017) believes that art emerges where a continuous line is born.

Consequently, the initial task of a cultured vocal singing sound should be related to the manifestation of certain continual mental processes that are not directly associated with the production and becoming of certain meanings but endow a singing sound with a desire for endless continuation, defining the quality of cantilena (lyricism) in it.

The problem of a singing sound in culture can be resolved to various degrees: it can include a number of other sounds directed towards comprehending certain spiritual meanings, or aimed at functions of application and service (part of rites, work activity, entertainment, etc.). Each genre and pattern of a singing sound can combine conscious and unconscious aspirations and can comprise of practical and higher spiritual meanings in a particular ratio. However, one thing is invariable: the utilitarian application of a person's singing abilities is a so-called 'by-product' of the development of a singing sound, while the evolution of singing culture is determined by an immanent source that is associated with the creative origin of human existence and is inherent in and peculiar to its nature.

To identify this connection, the authors referred to M. Heidegger's "The Origin of the Work of Art" (2013), whose conclusions can be extrapolated to a singing sound.

\section{Singing Sound as a Work of Art}

M. Heidegger conducts a comparison of things, products and artistic creations. In Heidegger's interpretation, the concept of a 'thing' is rather broad: it implies everything existent. The definition of a 'thing' as 'formalized matter' turns it into a product that is 
characterized by the quality of 'formedness'. Heidegger views this quality as something intermediate between a thing (as simply formed matter) and an artistic creation. An artistic creation is also formed matter that possesses the quality of 'self-sufficiency' instead of 'efficiency'.

Heidegger draws attention to the fact that a creation is always the carrier of 'something' that is not presented explicitly. He studies Van Gogh's painting of worn-out shoes with broken laces. The artist clearly implies that there is a kind of mystery and understatement behind this pictorial shabbiness. These shoes are a symbol that stands for the presence of a certain missing character that can be interpreted in multiple ways. Behind the shoes, a viewer unwittingly sees not just the fatigue and fatality of the life of a prototype, in particular, the prototype of a village worker but also the collective image of wearisomeness and the image of misery as such. As Heidegger explains, this image is made up of multiple symbolic representations existing in the artist's imagination. It is perceived as 'something' invisible that carries the image of the painting. The implementation of the author's idea on a specific material of art (as Heidegger notes it can be paints for an artist, a stone for an architect, or a sound for a musician) in the form of an artwork implies and involuntarily points to a much greater mental content inherent in the artwork than it is presented explicitly. Based on Heidegger's example of Van Gogh's painting, an entity refers to the two aspects of its being: the explicit and the implicit. Heidegger perceives truth as the Ancient Greek concept of 'aletheia', 'unconcealedness of Being', unlike the Roman understanding of truth as 'conformity'. True creation is potentially artistic and ambiguous. Truth is disclosed where a corresponding physical material of a work indicates a hidden, vast field of the understated or underexposed, which, together with the outspoken and expressed, constitutes the original wholeness.

The task of an artwork is to disclose the essence of a thing, i.e. its 'truth', as interpreted by Heidegger. 
This suggests that a singing sound hold also be viewed as a phenomenon of artistic creation. Its 'accomplishment' will be associated with the disclosure of essence. For a singing sound, essence lies in the person who produces the sound.

It is obvious that human 'essence' is immeasurably more complex and multi-dimensional than the essence of the most complex and multi-functional object. In its 'physical component', a singing sound must express a facet of human essence - perhaps, something secret, something deeply hidden both in a person's corporeity and consciousness.

Heidegger implicitly observes that essence stamped in an artistic creation has several dimensions. Later, this observation finds a philosophical reflection in his work. Analyzing the image of the Greek temple, the philosopher states that divine being, people's mentality, as well as the connections between the temple and nature (the rock, air) are imprinted in the architectural structure. It is possible to imagine a work of art as a kind of 'focus' in which various forms of being and its numerous essences (truths) meet (intersect and multiply). When it takes place, as M. Heidegger (2013) believes, the creation does not just 'expose' the portrayed object (as a product in its efficiency) but 'rebuilds' and 'erects' the entire world and captures its multifaceted being.

A singing sound, accordingly, expresses not only some 'essence' of a person but an individual countless interconnections of the internal 'worlds' and their external relations with the existent world. In such interrelations, one can observe the presence of at least the basic parameters of a creator's integral world and its 'revival' in an artistic creation, for example, a singing sound. Such a perception of this phenomenon allows revealing its fundamental quality - artistry.

In addition, Heidegger expresses the idea that truth does not exist in being as given but is disclosed to man in the complex dialectic of 'openness' and 'concealedness'. The self-movement of a work, which is explained by the desire to disclose the truth, is 
due to the fact that the 'materiality' of creation ('soil' in Heidegger's metaphorical interpretation) is too limited in its capabilities to express and retain the completeness of 'revival' in the creation of the world. As a result, an artist is forced to 'sort out' the methods and techniques that allow unfolding new aspects of innumerable connections with the world in a comparatively consistent manner. As a result, such an image of the world inevitably 'revives' by the principle of mosaic, fragments of which always somehow accrete into time and space. However, even in this case, the 'sound matter' will not to be able to express the completeness of the 'world' 'erected' in a creation and to represent it in absolute completeness - but only through a sequence of newer and newer aspects and sides. This reason conditions the procedural-dynamic nature of a creation that is fully met by a singing sound as a most complicated process, in which its actual sounding component and the system of artistic connections constantly seek for correlations.

Based on the arguments of Heidegger, the authors of the research come to the conclusion that a singing sound possesses the features of an 'artistic creation'. It expresses the 'essence' and 'truth' of a creator man; it is a source of abundance of connections established between man and the world (being-in-the-world); it is characterized as being 'composite' and having an idealisticmaterialistic nature, and bears the focus of an artist's aspirations to the 'truth' that exists in the constant transition from 'concealedness' to 'unconcealedness. These existential characteristics of a singing sound determine its artistry and procedural-dynamic nature.

The mobilenature of a singing sound as an artistic creation, which is conditioned by the 'dispute' between its 'semantic' and 'physical' beginnings, leads to the phenomenon of the 'inexpressible' in its dialectical connection with the expressible. Obviously, this pair can be viewed as a manifestation of the 'truth' in its constant transition from 'concealedness' to 'unconcealedness' (and vice versa). In this interpretation, the 'inexpressible' arises when an artist feels the impossibility to express some of the elusive connections of the existing holistic world in the materiality of their creation ('soil'). 
The'inexpressible' as the Source of Artistry of the Singing Phenomenon

The problems of the 'inexpressible' in the artistic culture and art were examined by Sintsov (2003). To clarify Heidegger's provisions regarding a singing sound, the authors of this research refer to Sintsov's work, "The Nature of the Inexpressible in Culture and Art".

Sintsov proves the provision that the 'inexpressible' is closely connected with the deep level of the unconscious called the 'psychoid unconscious' by C. Jung. Being the focus of primary bodily experiences that a person gains from encounters with the physical space of the world (tactile, gustatory, sound and other sensations), this level contains a 'memory' of real gestures (touches, strokes, pressure, etc.), as well as imaginary gestures that have only a very distant resemblance to a real gesture in terms of the qualities of repeatability and orientation. It is necessary to point out that the works of Penfield and Roberts (2016) reveal the dominant types of movements that occur when a person communicates with the surrounding world: hand and mouth gesturing. As shown by E.V. Sintsov in his research, at the deep layers of the unconscious, the mental images of these interactions, as a result of complex transformations, turn into a certain type of mental activity of a particular ethnic group and are manifested in the characteristic features of a certain artistic culture and, consequently, in a singing sound.

Based on Sintsov's concept, the 'revival' of a creator's world takes place during the expansion of an ornamental-like gesturalmental structure that makes up the 'composition' of an artist's erected world with its multiple layers. The author of "The Nature of the Inexpressible..." consistently proves that an ornament (in any form of its manifestation) is a form manifesting the 'inexpressible'. Sintsov believes that being present in any genuine work of art, it always manifests itself in one of the most important qualities that consists in modifying the seemingly complete form of the 
work and its meaningful and semantic 'content'. This function of the 'inexpressible' is defined as 'plasticizing' (the initial forms and content). Hence, its connections with the gestural activity arise. When analyzing this theory of the origin of the 'inexpressible', Sintsov mainly focuses on I. Kant's doctrine about the 'inner structure' of a work of art.

As Sintsov argues, it is the abundance of opportunities of creating a work of art that constantly influences the mental processes of an artist urging to look for more and more new methods and techniques of expressing the potential of opportunities in 'material'. In the imaginary mental space, there is a 'tangle' of powerful plasticizing energy where opportunities seem to 'outlive' one another in the struggle for living space. A number of following opportunities that have grown stronger immediately try to plasticize, i.e. to find weak points in the space conquered by the most potentially powerful opportunity of the moment and to change it as much as possible with the pressure of their energy. Sintsov proves this scientific hypothesis with the help of music since he believes that music resembles this chaotic gesture to some extent. One musical level perceives another level as a potential space in which it can expand its potencies, satisfy claims and thereby, if not destroy, then ensure the development of the initially born opportunity, enriching it with additional content.

At the same time, an artist never has the opportunity to materialize the inner form to the full. The work always contains the 'trace' of the under-embodied variants, i.e. the 'inexpressible'. An artist's experience in the process of creativity encourages the creator to make new works of art, endowing them with the quality of complexity, multi-dimensionality and 'nonlinearity', i.e. artistry.

Relying on this concept allows developing and deepening the notion of a singing sound as an artistic phenomenon resulting from the work of Heidegger. First, the notion of 'essence' is concretized and should be expressed in a work of art. For a singing sound, the essence of the person who produces the sound serves as such. It follows that essence should be understood as a person's mental 
and creative ability (one of the aspects of a human personality's 'efficacy').

Secondly, the connection between the complex and non-linear processes of mental movement helps to clarify the idea of the German philosopher about the 'erection of the world' in a work of art. Such a 'world' is a most complex and lively game of thought, imagination, feelings, intuition and the psychoid unconscious with its abundance of primary experiences of the world and a person's own physicality. Numerous networks of the 'components' of an artist's personality are involved in the creative act and thereby express the heterogeneous and multi-dimensional 'essence', its 'truth', 'erecting' the entire 'world' of some inner 'I'.

The erection of such a 'world' is not limited to the inner spaces of an artist's personality. The articulated sound, endowed with an internal structure, acquires an 'external' physical form. Then it starts to attract into its orbit the external spaces in which sound exists. An artist faces the task of correlating the internal and external forms, transitioning them in the constant 'dispute' between the actual sounding and something unfulfilled that is present in an artist's imagination. This contradiction causes a certain process of self-movement of the singing sound and does not end when the sound stops since some of the possibilities of the inner form always remain under embodied and exist as an aura of the 'inexpressible'. Obviously, this aura is somehow preserved after articulation as well, influences the artist's thinking and encourages a new act of creativity in sound.

Sintsov's concept makes it possible to define the origin of a singing sound as an artistic creation that determines its selfmovement. It is located in the deep layers of the subconscious and the psychoid unconscious, representing a certain center for a person's ornamental mental-gestural activity ('the inexpressible'). 
Singing Sound in the Context of the 'inexpressible' (the Aspect of Self-Movement)

The analysis of a singing sound from the position of the selected theories leads to the emergence of the procedural-dynamic concept of a singing sound that includes the following three main stages of uniform existence:

- presounding, in which the inner aspect of an artist's 'world' is activated, the gestural activity of their psychoid unconsciousness is awakened, and the whole richness of the inner structure of the future sound is formed;

- actual sounding, when the inner form 'materializes' part of its potencies, attracting in this process the complex dimensions of the outer 'world'. This period of a constant 'dispute' between the sound material of embodied and unrealizable opportunities, which determines the selfmovement of a singing sound and the peculiarities of an artist's efforts to translate the under-embodied into art ('techne);

- post-sounding, in which the creator experiences not only the flow of unfulfilled sounding opportunities (the 'inexpressible') but goes through (in the imagination) the success and failures of the creative experience anew.

When analyzing this concept in detail, it is necessary to point out that the 'inexpressible' is the origin of the creative activity that accompanies the birth of a singing sound (Sintsov).

Since a person already has bodily experience associated with sound, for example, the experience of sound emanating at the moment of birth directly from the body irrespective of anything else, a person can imagine this sound. This sound can last for some time in the consciousness but the remaining unrealized gestural intentions coming from the mental-gestural 'web' ('tangle') immediately begin to attack and plasticize (Sintsov, 2003). In this case, the first element of a 'non-equilibrium identity' reveals itself, 
arising between the opportunities of an imaginary sound space (not articulated yet) and the plasticizing efforts coming from within the mental-gestural 'web'. The imaginary space cannot unfold and 'hold' all the potential opportunities, which is explained by the fact that there are so many of them and their plasticizing potency is so great that they quickly crush this imaginary sound space, continuing to destroy it with the unrealized potency directly in the web just like during its existence.

The authors of the research mark this stage as the initial stage in the process of the creative self-movement of a singing sound. A singer begins to look for all sorts of real spaces where the energetically charged mental-gestural 'tangle' strives to take shape. A person's own body primarily becomes such a space.

Depending on which physical resonator a sound is directed to, it acquires different qualities and is characterized by a different length, different timbre and different strength of sounding. Despite the fact that a body is limited in its capabilities, the voice that born out of the body expands its limits and scope in some way. It exists in the body, with the body and outside the body at the same time because voice is separated from the body, it is carried away by the wave of sounds and is perceived as a separate phenomenon, for example, in the form of an echo. Belonging to the human physical-mental nature, a singing sound is itself a physical-mental phenomenon and, thus, it is a unique space where the mentalgestural 'tangle' can realize its potential.

The transition of an imaginary sounding space, in which the capabilities of the psychoid unconscious are partially activated, into real sound is explained by the resolution of the 'non-equilibrium identity' that is further created. It arises between the inner form of a sound created in an imaginary space and other variants of mental images multiply enhanced due to the activity of other variants of mental images attacking and plasticizing this image. In a certain sense, their colossal energy 'pushes' the image of sound into reality so that a person can eventually comparatively differentiate 
and reflect their 'exhausted' presentiments and their practically indivisible diversification.

The task of sound that breaks forth into reality is to sound as long as possible and to reveal in its duration the entire richness of the gestural intentions of its imaginary inner form. Thus, arises another non-equilibrium identity forcing the sound to last and go on unfolding the opportunities hidden in itself and a person's mind. Since this process is a process of transitioning from hidden to revealed, from 'concealed' to 'unconcealed' in Heidegger's terms, at this stage of sounding, one of the defining tasks is to acquire a skillful 'techne' capable of ensuring the continuance of sound to demonstrate the entire potential of the inner form of sound. Although the German philosopher decidedly rejects the presence of a 'technological' component related to 'making', creating a 'product' in this concept, Greek researchers still referred to this component. It is no coincidence that art (the field of artistic creativity and works of art) and high craft (the world of crafts) can be defined in one world in many cultures.

Nevertheless, the duration of a singing sound is limited by the physiological potential of the human exhalation. That is why the process of searching for newer spaces that would extend the life of real a singing sound continues.

Each culture tries to solve this problem in its own way, although there are general trends in the development of all singing cultures. Many traditions extend the duration of a sound by adding other voices, choral singing that uses chain breathing. There are musical instruments that accompany the space of the singing sound and follow it in time. Natural environments comprise a separate level of plasticization. Words make up a significant level of coloration of a singing sound. The emergence of large-scale dramaturgical vocal and instrumental works like liturgies, oratorios, cantatas, as well as the opera is explained by the desire to recreate the boundlessness of sound. 
As a result, due to the unfolding of the ornamental-like structure of a musical work of art, whose numerous levels are attracted by the original singing sound obsessed with the desire to reflect the continuity of the 'inexpressible', it increases the duration of the sound and expands its volume. This takes place due to the increased loudness of the sound flow and the coverage of new spaces, as well as the increase of its internal powers and the compaction of its structure with multifold plasticization by various possibilities (heterophonic, polyphonic, rhythmic, melismatic, modal, harmonic, etc.). This moment, on the one hand, determines the degree of change of a singing sound and the entire musical culture over the course of historical time. This tendency always presupposes another, perhaps more important tendency: both sound and singing culture keep expanding their capabilities to express the human 'essence' and 'truth' and deepen the insight into the 'concealment' of truth.

Nevertheless, such a closely related development of these two most important areas in the development of human singing culture does not abolish their original contradiction, their 'dispute'. Irrespective of the capabilities accumulated by culture in regard to the 'sound matter', it still will not be able to express all the innermost depths of human essence - there are always hidden and concealed zones escaped from imagination. This contradiction is another 'non-equilibrium identity' that pushes from the inside the singing sound and the entire culture to qualitative transformations. Sound termination is one of the extreme manifestations of these transformations.

When the actual sounding is terminated, the singing sound does not stop its existence. Due to a multi-dimensional and sometimes extremely complicated 'erected world', the 'circumference' of the singing sound does not allow it to immediately and completely vanish into 'Nothingness'. Post-sounding is characterized by a mental 'still-sounding' of voice in a singer's mind and an involuntary comparative analysis between the mental image that was supposed to be embodied and its accomplished embodiment. All information 
that comes to a singer's mind during singing through the feedback channels through the auditory analyzer focuses again in a singer's consciousness and is supplemented by visual and physical sources of sensations. All accomplished and potential opportunities are checked for congruence.

While this mental comparison is taking place, the 'stillsounding' gradually fades away and dissolves under the pressure of the numerous potential intentions that were not realized by the singing sound and still mentally try to plasticize it and eventually turn it into Nothingness. This is how a singer realizes that their initial pre-sounding idea was not fully materialized in real sounding. In this situation, the following 'non-equilibrium identity' reveals itself between the 'Nothingness' of the singing sound and the 'Being' of the mental-gestural 'tangle' that has accumulated an even greater energy potential as a result of the experience of the singing postsound and is again trying to realize its failed completeness through the artistic image of the singing sound.

Thus, a singing sound develops from itself, passes through the following stages: 'pre-sounding - sounding - post-sounding', and continues to be associated with an imaginary mental-gestural 'tangle' at every moment of its actual existence. That is, it is the 'inexpressible' and its aura that are constantly present and hold all the stages of the creation of a singing sound and its 'composite' structure in an organic unity as an artistic creation.

The relationships revealed between the singing phenomenon and the deep layers of the unconscious, and the creation of the concept of its 'being' allow considering the importance of a singing sound in culture from a new perspective. The surveys of modern Russian (Menchikov, 2013;Sintsov, 2003) and foreign (Bicknell, 2015; Cisney, 2014; Reznikoff, 2004; Schaefer, 2000)scholars, devoted to man's mental and creative activity, can be supplemented with the finding of this research on the singing phenomenon. The problem of the transfer from a singer's personal experience to the social level with the goal of its preservation and retransmission in culture still remains unsolved. 


\section{Conclusion}

Considering a singing sound as an 'artistic creation', the authors of the research came to the following conclusions regarding its essence. Singing sound is filled with a person's various connections with surrounding spaces (to put it in Heidegger's terms, this property can be formulated as 'restoration of the world'). Following the philosopher's reflections on the difference between a 'composition' and a 'thing', the authors of the research explained how singing sound differs from any other sound that is only characterized by 'efficiency', i.e. practical use and purpose. Singing sound not only 'restores the world' but also makes man the center of this world since it is focused, first of all, on revealing man's 'essence' and the 'truth' about oneself. As proved by the German philosopher, truth manifests itself only in the light of 'concealedness' and 'nonconcealedness'; it determines the procedural-dynamic plan of an artistic creation and thus of the singing sound.

Striving for self-expression in sound and comprehension of their 'essence' through a sound creation, a singer unfolds in time the facets of an idea-accomplishment. However, such an unfolding is never able to accommodate a person's numerous connections with the existent world, therefore, there is always a contradiction in the creation (a singing sound) - a contradiction between the physical limitation of the sound and its state of being full of 'essence'. Thus, the singing sound is linked with the 'inexpressible', the source of its self-movement. The 'inexpressible' accompanies the existence of a singing sound and combines it into an integral unity in the singer's consciousness, which takes place through self-movement by the 'pre-sounding - sounding - post-sounding' pattern as a result of overcoming a number of 'non-equilibrium identities', testing qualitative transformations at each stage.

Artistry and the connection with the 'inexpressible' (rooted in the psychoid unconsciousness) are the main ontological and aesthetic qualities of a singing sound. They allow defining a 
singing sound as an important phenomenon in human existence, associated with man's spiritual and creative potential.

Revealing the characteristics of this basic element of singing culture can greatly contribute to further research on the problems of singing culture, giving an opportunity to conduct a study in the context of a singing sound as an existential phenomenon.

\section{References}

Andguladze, N. (2002). Homo cantor: Sketches of vocal art. Retrievedfrom https://new.poiclub.net/books/andguladze-homocantor/(Accessed on September 13, 2018).

Losev, A.F. (2018). Music as a subject of logic. Retrieved from http:// litresp.ru/chitat/ru/\%D0\%9B/losev-aleksej-fedorovich/forma-stiljvirazhenie/4 (Accessed on September 13, 2018).

Lysenko, S.Y. (2013). The peculiarities of the revival of the composer's idea in a musical text in the artistic process of M. Musorgsky.

Fundamental research, 11(9): 1934-1940.

Menchikov, G.P. (2013). Neoclassical philosophy: essence, content, meaning. Scientific notes of Kazan University. Series of Humanities, 155(1): 105-116.

Pavlov, I.I. (2015). The composing technique and the inexpressible: on the philosophy of L. Wittgenstein's music. Newsletter of Tomsk State University. Philosophy. Sociology. Political Science, 4(32): 326-332. Sintsov, E.V. (2003). The mental-gestural nature of the unconscious manifested in ornamental forms of art. Retrieved from www.phil63. ru/category/4-mixtura-verborum-2003/ (Accessed on August 16, 2018).

Stanislavski, K. (2017). Work on oneself in the creative process of feeling. Art as reflection and cognition of life. Moscow: Eksmo-Press. Bicknell, J. (2015). A philosophy of song and singing: an introduction. London and New York: Routledge. Taylor \& Francis Group. 
Ontological and Aesthetic Qualities of a Singing Sound

Tatyana Gordeeva • Zagid Azhimov • Raushania Mirnaya • Alfia Voznesenskaya

Cisney, V.W. (2014). Derrida `s Voice and Phenomenon (Edinburgh Philosophical Guides EUP).Edinburgh: Edinburgh University Press. Heidegger, M. (2013). The Origin of the Work of Art. Poetry, Language, Thought. New York: Harper Collins Publishers Inc.

Khan, H.I. (1996). The Mysticism of Sound and Music: The Sufi Teaching of HazratInayat Khan. Boulder, Colorado: Shambhala Dragon Editions.

Penfield, W., Roberts, L. (2016). Speech and Brain Mechanisms. Princeton: Princeton University Press.

Reznikoff, Je. (2004). On primitive elements of musical meaning. JMM, 3, Fall 2004 - Winter 2005,Section 2. Retrieved from http://www. musicandmeaning.net/issues/showArticle.php?artID=3.2 Rogers, C.K. (1893). The philosophy of singing. Kansas city, Missuri: Harper \& Brothers.

Schaefer, J. (2000). "Songlines": vocal traditions in world music. In Potter, J. (Eds.). The Cambridge Companion to Singing. Cambridge: Cambridge University press. 